\title{
MucR Is Required for Transcriptional Activation of Conserved Ion Transporters to Support Nitrogen Fixation of Sinorhizobium fredii in Soybean Nodules
}

\author{
Jian Jiao, ${ }^{1,2,3}$ Li Juan Wu, , ,2,3 Biliang Zhang, ${ }^{1}$ Yue Hu, ${ }^{1,2,3}$ Yan Li, ${ }^{1,2,3}$ Xing Xing Zhang, ${ }^{1,2,3}$ \\ Hui Juan Guo, ${ }^{1,2,3}$ Li Xue Liu, ${ }^{1,2,3}$ Wen Xin Chen, ${ }^{1,2,3}$ Ziding Zhang, ${ }^{1}$ and Chang Fu Tian ${ }^{1,2,3}$ \\ ${ }^{1}$ State Key Laboratory of Agrobiotechnology, and College of Biological Sciences, China Agricultural University, Beijing, China; \\ ${ }^{2}$ Key Laboratory of Soil Microbiology, Ministry of Agriculture, China Agricultural University, Beijing, China; and ${ }^{3}$ Rhizobium \\ Research Center, China Agricultural University, Beijing, China
}

Submitted 22 January 2016. Accepted 10 February 2016.

To achieve effective symbiosis with legume, rhizobia should fine-tune their background regulation network in addition to activating key genes involved in nodulation (nod) and nitrogen fixation (nif). Here, we report that an ancestral zinc finger regulator, MucR1, other than its paralog, MucR2, carrying a frameshift mutation, is essential for supporting nitrogen fixation of Sinorhizobium fredii CCBAU45436 within soybean nodules. In contrast to the chromosomal mucR1, mucR2 is located on symbiosis plasmid, indicating its horizontal transfer potential. A MucR2 homolog lacking the frameshift mutation, such as the one from $S$. fredii NGR234, can complement phenotypic defects of the mucRI mutant of CCBAU45436. RNAseq analysis revealed that the MucR1 regulon of CCBAU45436 within nodules exhibits significant difference compared with that of free-living cells. MucR1 is required for active expression of transporters for phosphate, zinc, and elements essential for nitrogenase activity (iron, molybdenum, and sulfur) in nodules but is dispensable for transcription of key genes (nif/fix) involved in nitrogen fixation. Further reverse genetics suggests that $S$. fredii uses high-affinity transporters to meet the demand for zinc and phosphate within nodules. These findings, together with the horizontal transfer potential of the mucR homolog, imply an intriguing evolutionary role of this ancestral regulator in supporting nitrogen fixation.

Interactions between bacteria and eukaryotic hosts have driven the emergence of complex life forms and many important evolutionary innovations (Toft and Andersson 2010). Rhizobia induce the formation of new legume organs called nodules, which rhizobia colonize intracellularly and in which

\section{J. Jiao and L. J. Wu contributed equally to this work.}

RNA-seq data is available in the National Center for Biotechnology Information Sequence Read Archive server under accession number PRJNA302586, and the complete genome sequence of CCBAU45436 has been deposited under accession number PRJNA285929.

Corresponding author: C. F. Tian; Telephone: +8610 62734008; Fax: +86 10 62734008; E-mail: cftian@cau.edu.cn

*The $\boldsymbol{e}$-Xtra logo stands for "electronic extra" and indicates that four supplementary figures, three supplementary tables, and one supplementary dataset are published online.

(c) 2016 The American Phytopathological Society atmospheric nitrogen is reduced to ammonium in specialized rhizobial cells (bacteroids). In exchange for reduced nitrogen from bacteroids, the legume provides bacteroids with a carbon source and essential nutrients (Udvardi and Poole 2013). Rhizobia belong to more than 100 species from $\alpha$ - and $\beta$-proteobacteria and diverged much earlier than the advent of legumes (Peix et al. 2015; Turner and Young 2000). How could such diverse bacteria evolve into microsymbionts of legumes? This has been largely explained by the horizontal transfer of key symbiosis genes, including nod genes involved in biosynthesis of nodulation factors and nif/fix genes essential for adaptation to the microaerobic nodule environment and nitrogen fixation (MassonBoivin et al. 2009; Sullivan and Ronson 1998; Sullivan et al. 1995).

It has been demonstrated that the acquisition of key symbiosis genes essential for nodulation (nod) and nitrogen fixation (nif/fix) is not enough to confer a symbiotic phenotype to recipient pathogen Ralstonia solanacearum (Marchetti et al. 2010). Although modifications of certain virulence regulators in the recipient $R$. solanacearum can make this bacterium rapidly evolve symbiotic traits, i.e., nodulation and intracellular infection, the evolved clones do not fix atmospheric nitrogen (Guan et al. 2013; Marchetti et al. 2010). The acquired key symbiosis genes nod and nif/fix have been well studied, but the mechanisms by which recipient genomes evolve to completely incorporate these foreign symbiosis functions remain largely unexplored (Agron et al. 1993; Batut et al. 1989; David et al. 1988; Remigi et al. 2015; Roche et al. 1996).

Sinorhizobium fredii is well-known for its ability to nodulate on diverse legume hosts and is the major microsymbiont of cultivated and wild soybeans in alkaline-saline soils in Asia (Han et al. 2009; Man et al. 2008; Pueppke and Broughton 1999; Wu et al. 2011a; Zhang et al. 2011). Moreover, S. fredii strains have been successfully used as soybean inoculants under these soil conditions (Albareda et al. 2009; Rodríguez-Navarro et al. 2003). Here, we report that the mucR1 mutant of $S$. fredii forms ineffective nodules on soybean, though nif/fix genes are actively transcribed in bacteroids of this mutant. mucRl encodes a conserved $\mathrm{C}_{2} \mathrm{H}_{2}$ zinc finger-bearing transcriptional regulator, MucR/RosR, that is recently proposed as the putative ancestor of eukaryotic zinc finger structure through horizontal gene transfer (Baglivo et al. 2009; Bouhouche et al. 2000; Netti et al. 2013). Genetic evidence suggests that the observed symbiotic defects of the mucRl mutant is largely dependent on a frameshift mutation in $m u c R 2$, the second copy of the $m u c R$ gene localized in a plasmid region with typical features of horizontal transfer. Then, RNA-seq analysis was used to investigate the regulon of MucR1 
under both free-living and symbiotic conditions. The implication of MucR1-regulated genes encoding ion transporters in supporting nitrogen fixation were discussed and demonstrated by reverse genetics on representative genes.

\section{RESULTS AND DISCUSSION}

Identification of $m u c R l$ as an essential player in symbiotic interaction between $S$. fredii CCBAU45436 and soybean.

A mucR $1:: \operatorname{Tn} 5$ mutant forming nonmucoid colonies was identified in a Tn5 mutant library of $S$. fredii CCBAU45436, and the link of the transposon insertion and the nonmucoid phenotype was demonstrated using the mucRl deletion mutant (Supplementary Fig. S1). The mucRl deletion mutant was further inoculated on soybean to test its symbiotic performance (Fig. 1A). Nodule number induced by the mucRl mutant was around two times that formed by CCBAU45436 and these nodules showed reduced fresh weight per nodule (Table 1) ( $t$ test, $P$ value $<0.001$ ). Moreover, nodules formed by the $m u c R 1$ mutant were ineffective, as indicated by yellow leaves and reduced shoot dry weight that was indistinguishable from the uninoculated control (Fig. 1A; Table 1). The symbiotic defects of the mucRl mutant could be recovered by introducing pBmucRl expressing wild-type mucRl (mucRl/pBmucRl) but not by the empty vector pBBR1MCS-2 (Fig. 1A; Table 1). Briefly, shoot dry weight and nodule fresh weight were significantly increased, while the number of nodules was significantly decreased in plants inoculated with $m u c R 1 / \mathrm{pBmucR} 1$ compared with the mucRl mutant ( $t$ test, $P$ value $<0.01$; Duncan's test, $\alpha=0.05)$. Although the number of nodules induced by $m u c R 1 / \mathrm{pBmucR} 1$ was slightly higher than that of plants inoculated with wild-type CCBAU45436 ( $t$ test, $P$ value $<$ 0.05; Duncan's test, $P$ value $>0.05$ ), nodule fresh weight (per nodule) and shoot dry weight were not statistically different
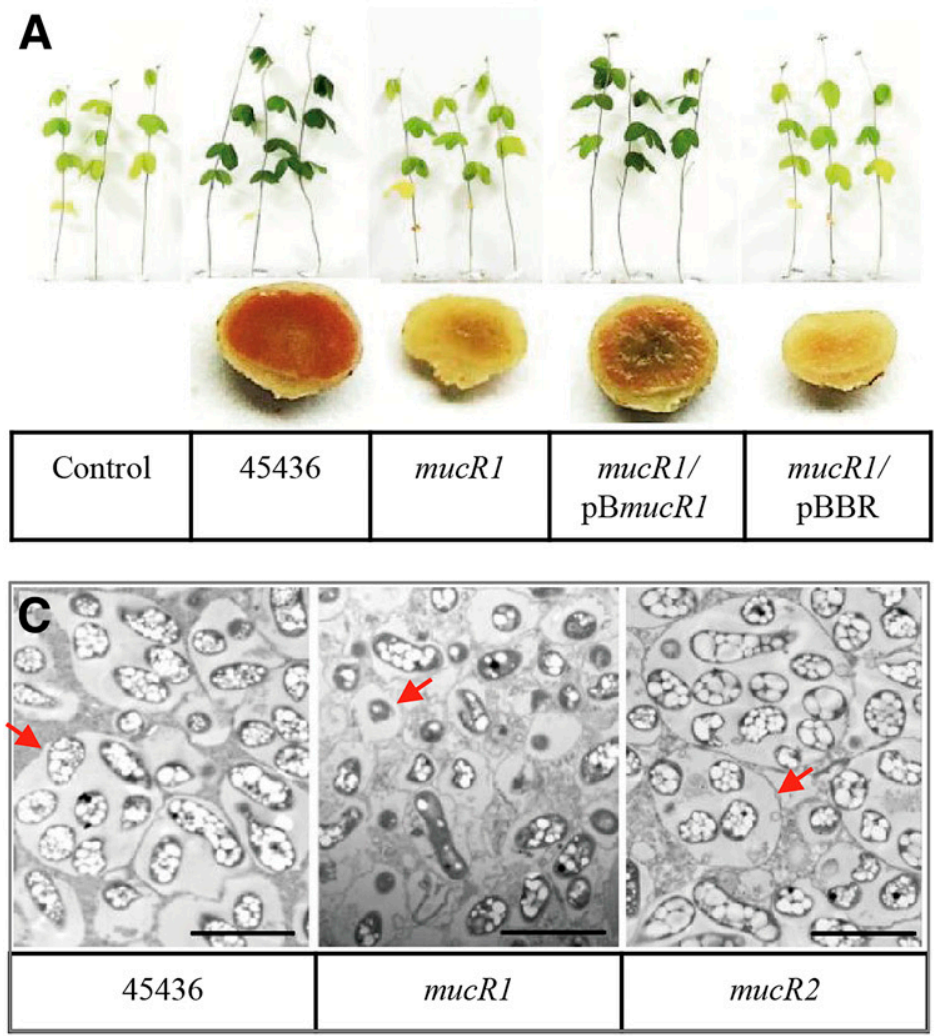

B

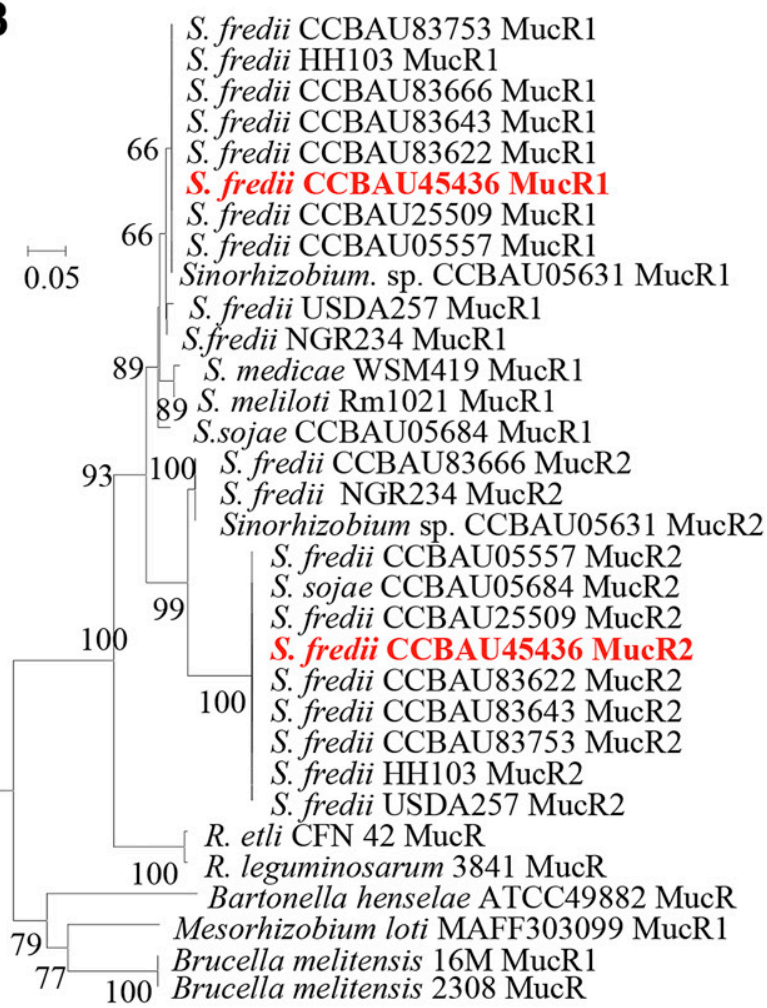

S. fredii CCBAU83666 MucR1

S. fredii USDA257 MucR1

fredii NGR234 MucR1

S. meliloti Rm1021 MucR1

S.sojae CCBAU05684 MucR1

S. fredii NGR234 MucR2

Sinorhizobium sp. CCBAU05631 MucR2

S. fredii CCBAU05557 MucR2

S. fredii CCBAU83622 MucR2

S. fredii CCBAU83643 MucR2

S. fredii CCBAU83753 MucR2

S. fredii $\mathrm{HH} 103 \mathrm{MucR} 2$

$S$. fredii USDA257 MucR2

CFN 42 MucR

100 Brucella melitensis $2308 \mathrm{MucR}$
D
340

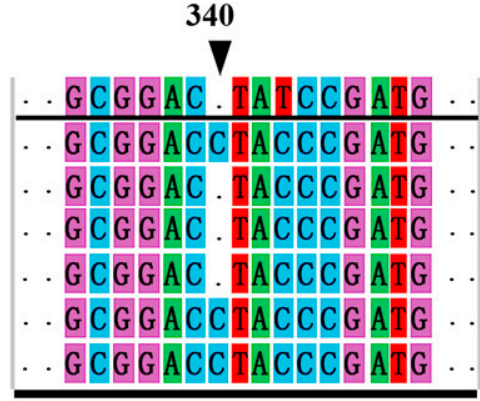

DNA (partial)

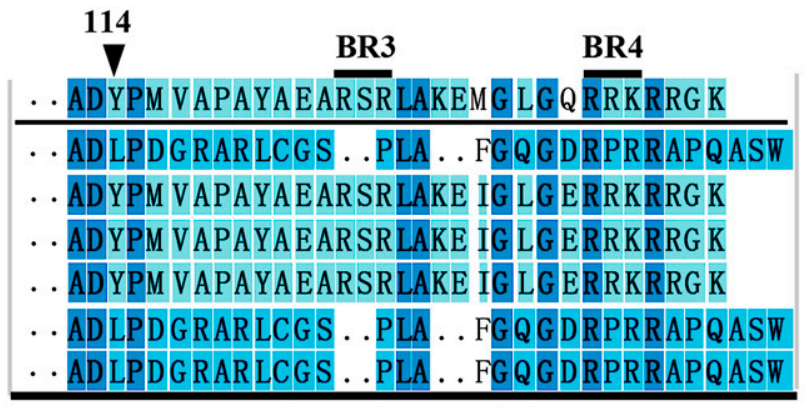

Protein (partial)

Fig. 1. mucR1 rather than mucR2 is essential for the symbiosis between Sinorhizobium fredii CCBAU45436 and soybean. A, Soybean shoot and nodule halves. B, Neighbor-joining phylogenetic tree of MucR homologs. Scale bar $=5 \%$ substitution per site. Bootstrap values above 60 are shown. C, Ultrathin sections of soybean nodules formed by CCBAU45436, the mucR1, or mucR2 mutant. Pictures of ultrathin sections of 30-days postinoculation nodules were obtained under transmission electronic microscopy. Scale bar indicates $2 \mu \mathrm{m}$. Red arrows point to symbiosome membrane. D, Sequence analysis of MucR homologs. The triangle indicates the insertion site (340C) in certain mucR2 genes and the start position (114L) of the corresponding frameshift event in protein sequences. BR3 and BR4 are two basic regions conserved among MucR homologs without the insertion mutation. 
from those of plants inoculated with CCBAU45436 $(t$ test and Duncan's test, $P$ value $>0.05)$. Sequence analysis revealed that mucRl encodes a conserved $\mathrm{C}_{2} \mathrm{H}_{2}$ zinc finger-bearing transcriptional regulator MucR (or RosR), in which the $\mathrm{C}_{2} \mathrm{H}_{2}$ zinc-finger domain and four basic regions (BR), BR1 at the $\mathrm{N}$-terminus and BR2-4 at the C-terminus, form a large domain essential for DNA-binding (Bouhouche et al. 2000; Malgieri et al. 2015; Netti et al. 2013). Although the MucR homolog has been reported as a pleiotropic regulator involved in motility and the production of exopolysaccharides in the model organism $S$. meliloti, its mucR mutant is indistinguishable from the wild-type strain in terms of symbiotic performance (Keller et al. 1995; Bahlawane et al. 2008). However, it was reported that the MucR homolog contributes to competitive nodulation of Rhizobium etli on Phaseolus vulgaris (Bittinger et al. 1997). The mucR mutant of Rhizobium leguminosarum bv. trifolii forms less than half the number of nodules compared with the wild-type strain on clover (Janczarek et al. 2010). Moreover, inoculated clover plants are yellowish, indicating inefficient symbiosis (Janczarek et al. 2010). These discrepancies between different species in terms of symbiotic phenotype might be partially due to the differences in their genome content, including the varying number of MucR copies as indicated in Supplementary Figure S2.

\section{mucR2 in $S$. fredii CCBAU45436 is not functionally equivalent to mucRI due to a frameshift mutation.}

In the genome of CCBAU45436 or its closely related strains and species, such as $S$. fredii strains NGR234 and HH103 and S. sojae CCBAU05684 (Schmeisser et al. 2009; Tian et al. 2012; Weidner et al. 2012), there are two MucR copies showing high similarity to each other (such as $83 \%$ in DNA between two copies of CCBAU45436). As shown in the phylogenetic tree of MucR (Fig. 1B), MucR1/MucR2 may originate from a recent duplication event in these Sinorhizobium strains, in contrast to one or more other distantly related homologs found in several species or strains. Moreover, in contrast to the chromosomal $m u c R 1, m u c R 2$ is always localized on the symbiosis plasmid and is surrounded by highly conserved sequences (Supplementary Fig. S3), including $y 4 a Q$ coding a transposase of the IS66 family and nodD1 required for the expression of nod genes (Kobayashi et al. 2004), suggesting potential horizontal transfer of mucR2 between strains or species. In line with this hypothesis, identical $m u c R 2$ genes were found among $S$. sojae CCBAU05684 and
S. fredii strains CCBAU45436, HH103, and USDA257 or between S. fredii CCBAU83666 and Sinorhizobium sp. CCBAU05631. The mucR2 gene of $S$. fredii NGR234 shows 99.1 and $99.5 \%$ similarity to these two groups, respectively.

A $m u c R 2$ mutant and a $m u c R 1 R 2$ double mutant were further constructed and tested for their symbiotic phenotype on soybean. As shown in Table 1, the mucRIR2 double mutant showed similar symbiotic defects on soybean compared with the $m u c R 1$ mutant. The mucR2 mutant was indistinguishable from CCBAU45436 regarding nodule number, fresh weight per nodule, and shoot dry weight ( $t$ test, $P$ value $>0.05$ ). Furthermore, the symbiosome of soybean nodules formed by the $m u c R 2$ mutant is similar to that of CCBAU45436, containing multiple bacteroids, whereas each symbiosome formed by the mucRl mutant contains only one bacterial cell (Fig. 1C). Sequence analysis unveiled that there is an insertion mutation (340C) in mucR2 compared with $m u c R l$ in CCBAU45436 (Fig. 1D). The same insertion was also found in mucR2 of $S$. fredii strains HH103 and USDA257 and S. sojae CCBAU05684 but not in S. fredii strains NGR234 and CCBAU83666 and Sinorhizobium sp. CCBAU05631. This insertion caused a frameshift event starting from the 114th amino acid of the MucR homologs (Fig. 1D) and may destroy two basic regions (BR3 and BR4) that are necessary for DNA-binding activity of MucR/RosR (Baglivo et al. 2009). Therefore, symbiotic defects of the mucRl mutant are likely due to mucR 2 carrying the insertion mutation being unable to fulfill the function of MucR/RosR.

To test this hypothesis, various mucR homologs with or without the insertion mutation at the 340th base were introduced into the mucRl mutant, using pBBR1MCS-2. As indicated in Table 1, $m u c R$ homologs without the insertion mutation, such as wildtype $m u c R 1$ of CCBAU45436, mucR1 and mucR2 of NGR234, and the 340C-lacking mucR2 derivative of CCBAU45436, could restore the symbiotic performance of the mucRl mutant regarding nodule weight and shoot dry weight. In contrast, the mucRl derivatives harboring a 340C insertion mutation, point mutations in BR3 or without the BR4 region, and wild-type $m u c R 2$ of CCBAU45436 could not complement the symbiotic defects of the mucRl mutant (Table 1) ( $t$ test, $P$ value $<0.05)$.

The characteristic phenotypes, under free-living conditions, associated with the $m u c R$ mutants in all documented bacterial species are the nonmucoid (rough outer surface) colonies

Table 1. Responses of soybean plants to inoculation of Sinorhizobium fredii CCBAU45436 and its derivatives ${ }^{\mathrm{a}}$

\begin{tabular}{|c|c|c|c|c|}
\hline \multirow[b]{2}{*}{ Inoculant } & \multirow[b]{2}{*}{ No. of nodules ${ }^{b}$} & \multicolumn{2}{|c|}{ Nodule fresh weight (mg) } & \multirow[b]{2}{*}{ Shoot dry weight ${ }^{c}$} \\
\hline & & Per plant & Per nodule & \\
\hline WT & $9.1 \pm 0.8$ & $122.0 \pm 9.1$ & $14.4 \pm 1.5$ & $493.6 \pm 11.9$ \\
\hline Uninoculated control & - & - & - & $414.5 \pm 21.3 * *$ \\
\hline mucRl & $17.0 \pm 1.8^{* * *}$ & $91.4 \pm 7.4^{*}$ & $5.5 \pm 0.3 * * *$ & $421.6 \pm 22.9^{*}$ \\
\hline mисR2 & $10.3 \pm 1.0$ & $132.6 \pm 5.1$ & $13.9 \pm 1.2$ & $451.5 \pm 29.7$ \\
\hline mucRlR2 & $15.1 \pm 1.1 * * *$ & $90.7 \pm 3.9 * *$ & $6.1 \pm 0.5^{* * *}$ & $402.0 \pm 15.1 * * *$ \\
\hline mucR1/pBBR1MCS2 & $17.9 \pm 1.3^{* * *}$ & $93.2 \pm 4.8^{*}$ & $5.3 \pm 0.2 * * *$ & $441.4 \pm 16.6^{*}$ \\
\hline mисR1/pBmисR1 & $11.4 \pm 0.6^{*}$ & $135.7 \pm 5.1 *$ & $12.3 \pm 0.9$ & $524.4 \pm 16.4$ \\
\hline mисR1/pBmисR2 & $15.6 \pm 1.9^{* *}$ & $86.8 \pm 6.8 * *$ & $6.0 \pm 0.5^{* * *}$ & $382.8 \pm 27.4 * *$ \\
\hline mисR1/pBmисR $1+340 C$ & $16.2 \pm 1.4 * * *$ & $79.6 \pm 5.0 * * *$ & $5.2 \pm 0.4 * * *$ & $376.6 \pm 22.3 * * *$ \\
\hline mисR1/pBтисR2-340C & $10.5 \pm 0.8$ & $132.9 \pm 5.6$ & $13.4 \pm 1.2$ & $479.2 \pm 29.2$ \\
\hline mисR1/pBтисR1-NGR234 & $10.0 \pm 0.7$ & $119.2 \pm 6.1$ & $12.4 \pm 1.4$ & $483.7 \pm 13.8$ \\
\hline mисR1/pBтисR2-NGR234 & $9.8 \pm 1.0$ & $116.6 \pm 4.6$ & $12.8 \pm 1.4$ & $494.1 \pm 18.6$ \\
\hline тисR1/pBтисR1-BR3PM & $15.0 \pm 1.0^{* * *}$ & $73.8 \pm 8.2 * * *$ & $5.2 \pm 0.5^{* * *}$ & $384.3 \pm 25.0 * * *$ \\
\hline тисR1/pBтисR1-BR4D & $16.3 \pm 1.2 * * *$ & $77.4 \pm 6.9 * * *$ & $5.0 \pm 0.5 * * *$ & $388.1 \pm 20.0 * * *$ \\
\hline mисR1R2/pBтисR1 & $10.9 \pm 0.7$ & $128.3 \pm 5.9$ & $12.4 \pm 1.1$ & $485.3 \pm 18.5$ \\
\hline тисR1R2/pBтисR2 & $15.5 \pm 1.6^{* *}$ & $94.6 \pm 7.6^{*}$ & $6.7 \pm 0.3 * * *$ & $405.6 \pm 25.2 * *$ \\
\hline
\end{tabular}

a Average \pm standard error of the means scored from ten plants. Similar results were obtained in three independent experiments. Significant difference compared with values of CCBAU45436 wild-type strain based on $t$ test is indicated. $*=P$ value $<0.05 ; * *=P$ value $<0.01$; and $* * *=P$ value $<0.001$.

b Nodules per plant.

c Shoot dry weight in milligrams per plant. 
(Bertram-Drogatz et al. 1998; Bittinger et al. 1997; Caswell et al. 2013; Janczarek and Skorupska 2007). As shown in Figure 2, the mucRl mutant and the mucRlR2 double mutant formed nonmucoid colonies similar to the exoA mutant that is unable to produce exopolysaccharides (EPS) (RodríguezNavarro et al. 2014). In contrast to truncated mucRl derivatives and the wild-type mucR2 from CCBAU45436, the wild-type $m u c R 1$ from CCBAU45436, mucR1 or mucR2 from NGR234, and various mucRl and mucR2 derivatives without the frameshift mutation can successfully restore the mucoid surface. Therefore, in the genome of $S$. fredii CCBAU45436, MucR2 may have lost the typical function of MucR/RosR due to a frameshift mutation.

The MucR1 regulon in nodules does not include nif/fix genes despite the $\mathrm{Fix}^{-}$phenotype of the mucRI mutant.

To reveal the underlying mechanisms of ineffective symbiotic performance of the mucRl mutant, RNA-seq transcriptomic analysis was carried out for bacteroids of this mutant and the wild-type CCBAU45436. This high-resolution technique uncovered 597 differentially expressed genes (DEG) (with a false discovery rate $[\mathrm{FDR}] \leq 0.001, \mid \log _{2}$ ratio $\mid \geq 1$ ) between the $m u c R 1$ mutant and CCBAU45436 in soybean nodule (Fig. 3A), to our knowledge, the largest regulon associated to MucR/RosR documented so far in bacteria (Bahlawane et al. 2008; Bittinger and Handelsman 2000; Caswell et al. 2013; Mueller and González 2011). Similarly, there were 621 DEG uncovered in tryptone yeast (TY) culture (Fig. 3A), resulting in a total of 1,076 DEG between the mucR1 mutant and CCBAU45436 under test conditions (Supplementary Dataset S1). To validate RNA-seq results, we performed quantitative reverse transcription-polymerase chain reaction (qRT-PCR) on 25 genes with different expression profiles (Supplementary Table S1). The RNA-seq results agree well with the qRT-PCR data from three independent biological replicates (Fig. 3B) and the Pearson correlation coefficient value is 0.891 ( $P$ value $<0.001)$.

Intriguingly, less than $10 \%$ of the DEG $(106$ of 1,076$)$ showed similar transcription profiles in both TY culture and soybean nodule (Fig. 3A). Further analysis disclosed that DEG in bacteroids of the mucRl mutant are enriched in COG (clusters of orthologous groups) categories $\mathrm{P}$ (inorganic ion transport and metabolism) and $U$ (intracellular trafficking, secretion, and vesicular transport) (Fisher's exact test, $P$ value $<0.001$ ) (Supplementary Table S2). By contrast, the enriched COG category is $\mathrm{N}$ (cell motility) under free-living conditions for the mucRl mutant compared with CCBAU45436 (Fisher's exact test, $P$ value $<0.001)$. This indicates that MucR1 is not a local regulator and transcriptomic analysis based on free-living cells of the mucRl mutant, as reported earlier for other bacteria, including S. meliloti (Bahlawane et al. 2008; Bittinger and Handelsman 2000; Caswell et al. 2013; Mueller and González 2011), is not enough to reveal a global picture of the MucR1 regulon, which can vary when facing different environmental stimuli.

Soybean plants inoculated with the mucRl mutant showed the typical phenotype of nitrogen starvation (Fig. 1A; Table 1) and only a trace level of nitrogenase activity, as measured using an acetylene reduction assay, could be detected from nodules induced by the mucRl mutant (Fig. 4A). However, RNA-seq suggests similar expression levels of nif/fix genes between the mucR 1 mutant and CCBAU45436 ( $\log 2$ ratio $<1$ for all nif/fix genes), though a slight expression difference in a few genes such as $n$ if $D$ was statistically significant $(\log 2$ ratio $=0.59$; FDR $<0.001)$. These results are also supported by qRT-PCR analysis of nifD (encoding dinitrogenase subunit), nifA (encoding a positive transcriptional regulator for nif genes), and fixA (encoding a component of electron transfer complex) (Fig. 4B). These

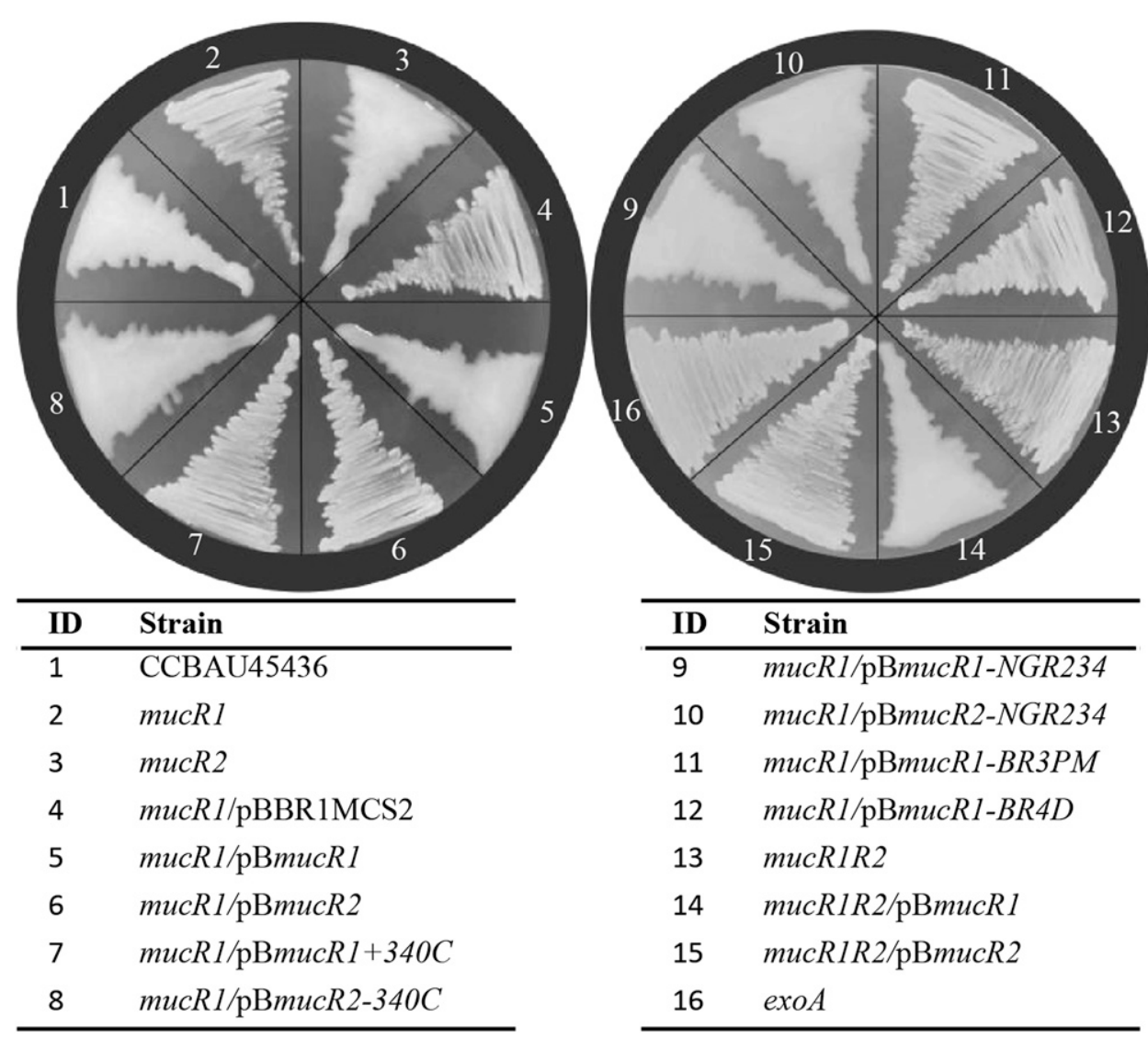

Fig. 2. Rough colonies of the mucR1 mutant depend on a frameshift mutation of mucR2 in Sinorhizobium fredii CCBAU45436. 
findings imply that nitrogen fixation genes are actively transcribed in bacteroids of the mucRl mutant and could not account for its symbiotic defects.

\section{Downregulation of ion transporters accounts for the $\mathrm{Fix}^{-}$phenotype of the mucRl mutant.}

Nitrogenases of rhizobia contain two components, the iron $(\mathrm{Fe})$ protein with a $[4 \mathrm{Fe}-4 \mathrm{~S}]$ cluster and the molybdenum-iron $(\mathrm{MoFe})$ protein with an $[8 \mathrm{Fe}-7 \mathrm{~S}]$ cluster and the FeMo cofactor $\left(\mathrm{MoFe}_{7} \mathrm{~S}_{9} \cdot\right.$ homocitrate) (Dixon and Kahn 2004). Earlier proteomic and biochemical analysis of symbiosome membrane in nodules uncovered the transport of iron, molybdenum, and sulfur (Clarke et al. 2014). In line with these findings, rhizobial genes encoding transporters of iron ( $a f u A B C, \log _{2}$ ratio above 6.0) (Chao et al. 2005; Chin et al. 1996), molybdenum $\left(\bmod A B C, \log _{2}\right.$ ratio $=1.0$ to 2.7$)$ (Delgado et al. 2006), aliphatic sulfonate $\left(\operatorname{ssu} A B C, \log _{2}\right.$ ratio above 4.2$)$, and aminoethane sulfonate (tauABC, $\log _{2}$ ratio above 5.0) (Sugawara et al. 2011; van der Ploeg et al. 1997) were up-regulated in
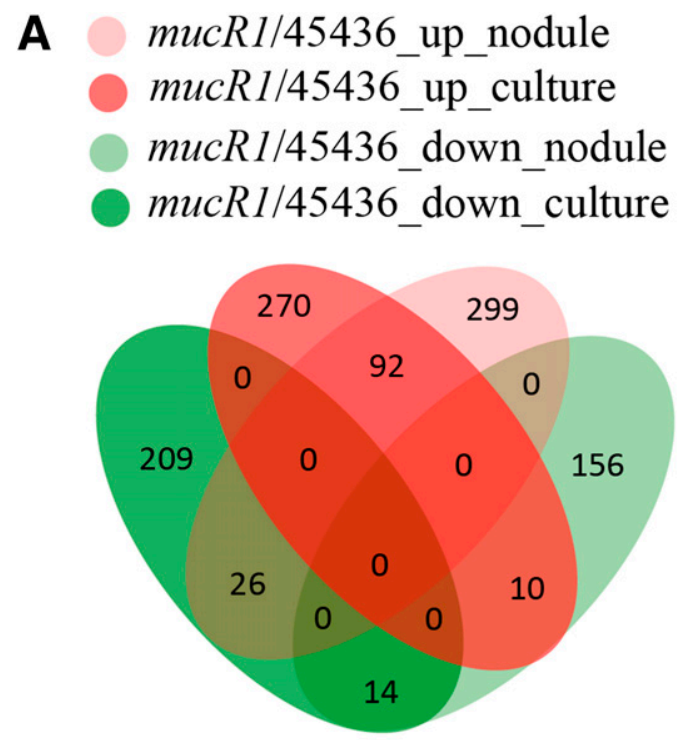

1076 DEGs

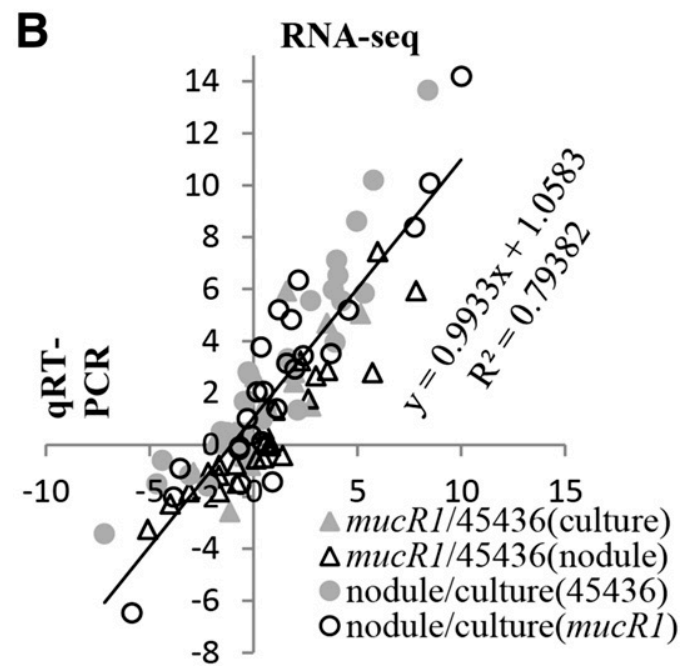

Fig. 3. Summary and validation of RNA-seq results. A, Summary of RNAseq results. B, Validation of RNA-seq results using quantitative reverse transcription-polymerase chain reaction (qRT-PCR) from three biological replicates. The $\log _{2}$-transformed expression ratios from RNA-seq (vertical axis) and qRT-PCR (horizontal axis) are shown. bacteroids of CCBAU45436 compared with free-living cells (FDR < 0.0001). However, in bacteroids of the mucRl mutant, these transporters were significantly down-regulated (Fig. 4C), implying that the defect of the $m u c R l$ mutant in nitrogen fixation might be partially due to the shortage of key elements essential for the functioning of nitrogenase.

The symbiosome isolated from soybean nodules has been demonstrated to uptake zinc from the medium, and GmZIP1, a soybean zinc transporter, is localized on symbiosome membrane (Moreau et al. 2002). znuA, znuB, and znuC encode the conserved bacterial zinc transport system importing zinc under low zinc conditions (Patzer and Hantke 1998; VahlingArmstrong et al. 2012), and they were strongly induced in CCBAU45436 bacteroids compared with free-living cells ( $\log _{2}$ ratio above 4 , FDR $\left.<0.0001\right)$. In bacteroids of the mucRl mutant, however, the expression level of $z n u A, z n u B$, and $z n u C$ was significantly down-regulated by onefold compared with CCBAU45436 bacteroids (FDR $<0.0001$ ). Soybean plants inoculated with the $z n u A$ mutant showed reduced shoot dry weight $(P$ value $<0.05)$ and increased nodule number $(P$ value $<0.01)$ (Fig. 4D and E), implying that the reduced supply of zinc, due to downregulation of $z n u A, z n u B$, and $z n u C$, might also contribute to the symbiotic defect of the mucRl mutant.

pstSCAB encoding a high-affinity phosphate transporter is involved in adaptation to phosphate starvation (Becker et al. 2004; Yuan et al. 2006) and is down-regulated in bacteroids of the mucRl mutant (Fig. 4C). Its deletion mutant, pst, exhibited symbiotic defects (Fig. 4D and E) $(P$ value $<0.05)$ similar to the mucRl mutant (Table 1). Other genes involved in phosphate starvation adaptation were also down-regulated in bacteroids of the mucRl mutant (Fig. 4C), such as regulatory genes phoU and $p h o B$ (Geiger et al. 1999), transporter genes ugpB, ugpA, ugpE, and $u g p C$ (sn-glycerol 3-phsphate) and $p h o C$, phoD, phoE, and phoT (phosphonate) (Hsieh and Wanner 2010), and btaA and $b t a B$ involved in the biosynthesis of phosphorus-free lipids diacylglyceryl-N,N,N-trimethylhomoserine (DGTS) (Geiger et al. 1999; Zavaleta-Pastor et al. 2010). Upregulation of these phosphate starvation genes has also been reported in $S$. fredii NGR234 bacteroids in both determinate nodules of Vigna unguiculata and indeterminate nodules of Leucaena leucocephala ( $\mathrm{Li}$ et al. 2013). It has been proposed that $p s t S$, pst $C$, pst $A$, and pstB and downstream regulatory genes phoU and $p h o B$ may form a putative operon (Yuan et al. 2006). phoU and $p h o B$ encode a chaperone and a key transcriptional regulator in phosphate starvation, respectively (Hsieh and Wanner 2010), and an in-frame deletion mutant of $p h o B$ was constructed. However, the $p h o B$ mutant of CCBAU45436 was not symbiotically defective compared with wild-type strain $(t$ test, all $P$ values $>0.05$ ) regarding nodule number (mean \pm standard error of the mean, $9.7 \pm 0.65$ per plant) and shoot dry weight $(448.4 \pm 24.62 \mathrm{mg}$ per plant) of inoculated soybean plants. PhoB positively regulates the transcription of phosphate starvation genes, including those involved in DGTS synthesis and $p s t S$, pst $C$, pst $A$, and pstB, while it represses the expression of a low-affinity phosphate transporter encoded by orfA-pit operon (Becker et al. 2004; Yuan et al. 2006). In bacteroids of the $m u c R l$ mutant in soybean nodules, phoB and pstS, pstC, pstA, and $p s t B$ were down-regulated, while the $\operatorname{orf} A$-pit operon was up-regulated. This is in contrast with the expression profiles of their homologs in bacteroids of $S$. meliloti in alfalfa nodules, in which the low-affinity transporter encoded by orfA-pit alone could support normal symbiotic functions of bacteroids (Yuan et al. 2006). These findings imply that bacteroids in nodules of soybean and alfalfa may face different levels of phosphate supply.

Genes involved in the assembly of pilus and three secretion systems (T1SS, T3SS-I, and T4SS-III) were up-regulated in the mucRl mutant (Fig. 4C). The T1SS is thought to simply transport 
A Acetylene reduction B
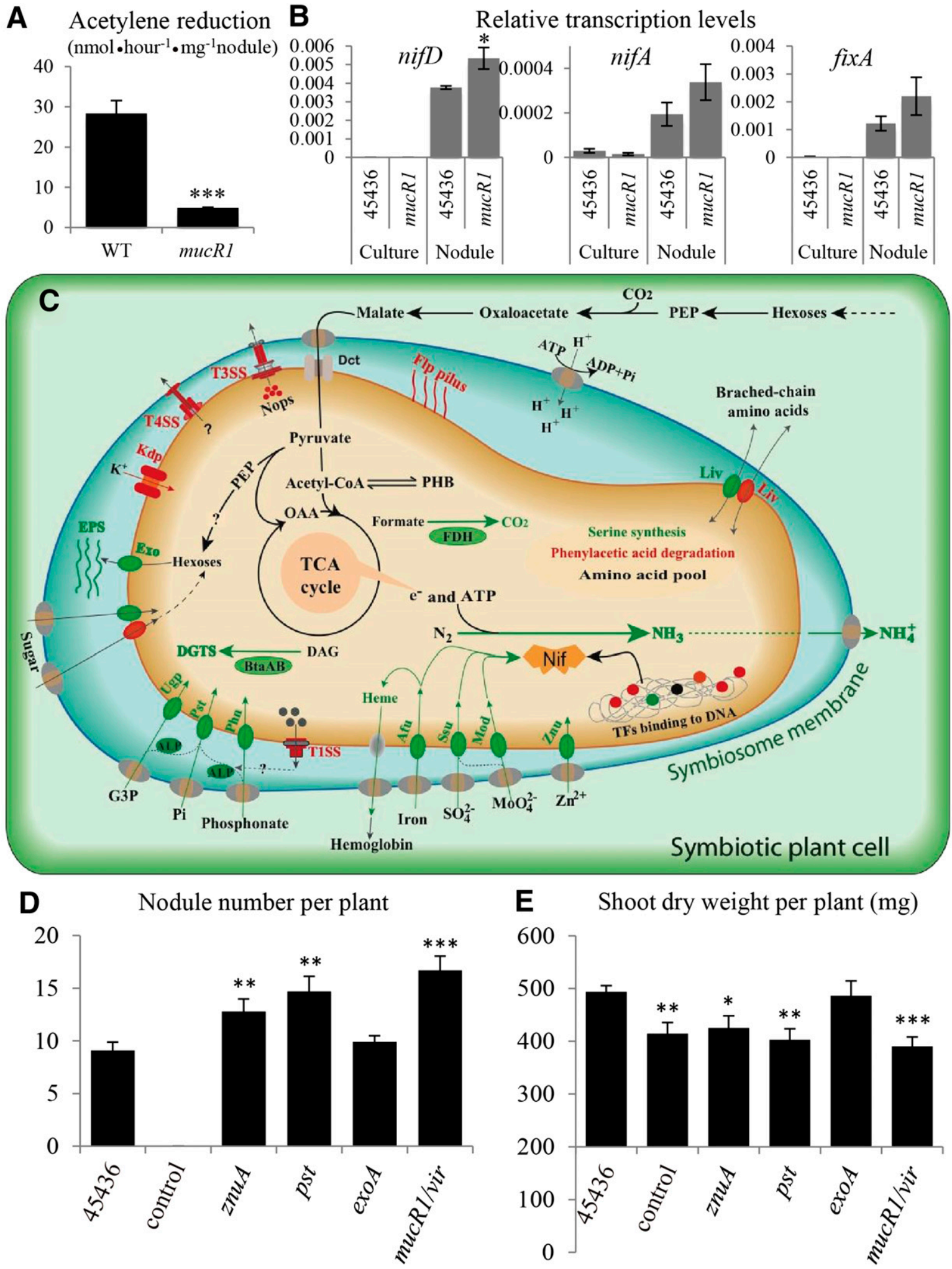

Fig. 4. MucR1 maintains the conditions essential for nitrogen fixation but not the expression of nif/fix genes. A, Nitrogenase activity as measured using an acetylene reduction assay on three biological replicates. B, Relative transcription level of nifD, nifA, and fixA compared with the $16 \mathrm{~S}$ ribosomal RNA gene (measured using quantitative reverse transcription-polymerase chain reaction on three biological replicates). C, Enrichment of differentially expressed genes in the inorganic ion transport and secretion system in bacteroids of the mucRl mutant compared with CCBAU45436. Up- and down-regulated genes are represented in red and green, respectively. EPS $=$ exopolysaccharide, ALP $=$ alkaline phosphatase, G3P $=$ sn-glycerol 3-phosphate, FDH $=$ formate dehydrogenase, DGTS = diacylglyceryl-N,N,N-trimethylhomoserine, DAG = diacylglycerol, and PHB = polyhydroxybutyrate. D, Nodule number and E, shoot dry weight per plant inoculated with Sinorhizobium fredii strains (10 plants were scored in each treatment and similar results were obtained in multiple independent experiments). Significant difference between the mean of each treatment and the corresponding value of CCBAU45436 is indicated $(t$ test: $*=P$ value $<$ $0.05, * *=P$ value $<0.01, * * *=P$ value $<0.001)$. Error bars represent standard error of the means. 
proteins outside of the cell (Nelson and Sadowsky 2015; Schmeisser et al. 2009). In S. fredii, the influence of T3SS-I on symbiosis with soybean happens at an early interaction stage, i.e., either increasing or reducing nodulation (Krishnan et al. 2003; Yang et al. 2010). The T4SS system can translocate DNA or protein substrates across the cell envelope (Cascales and Christie 2003), and the closest homolog of $S$. fredii T4SS-III has been reported to be required for conjugation but not for symbiosis of S. meliloti (Jones et al. 2007; Sugawara et al. 2013). In contrast to T1SS and T3SS-I, both of which were actively transcribed in CCBAU45436 bacteroids, T4SS-III were rarely transcribed in bacteroids of CCBAU45436 (reads per kilobase per million mapped reads [RPKM] below 25) but expressed in bacteroids of the mucRl mutant at levels (RPKM up to 6,294) comparable to nif/fix genes. Consequently, to relieve this burden in the mucRl mutant, the T4SS-III (vir) was deleted in the mucRl mutant. The mucRl/vir double mutant was still symbiotically defective, similar to the mucRl mutant regarding nodule number and shoot dry weight (Fig. 4D and E). Therefore, the unexpected high expression of T4SS-III might not be the key determinant of the symbiotic defect of the mucRl mutant.

In addition to above-mentioned genes encoding ion transporters and secretion systems, DEG also include those involved in the biosynthesis of EPS and serine, formate metabolism, phenylacetic acid degradation, and more (Fig. 4C). A Bradyrhizobium japonicum mutant lacking formate dehydrogenase activity was found to be capable of nodulating soybean and fixing nitrogen (Manian et al. 1982). EPS is important for rhizobial adaptations to diverse stresses and crucial for S. meliloti-Medicago symbiosis (Deaker et al. 2004; Skorupska et al. 2006). Although the expression of exo genes was down-regulated in bacteroids of the mucRl mutant compared with CCBAU45436, the exoA mutant defective in producing EPS (Fig. 2) formed an effective symbiosis with soybean plants (Fig. 4D and E). This indicates that the defect in producing EPS by the mucRl mutant, a typical phenotype observed in diverse bacteria (Bertram-Drogatz et al. 1998; Bittinger et al. 1997; Caswell et al. 2013; Janczarek and Skorupska 2007), may not lead to its impaired symbiotic performance.

\section{Conclusions.}

The rhizobium-legume symbiosis is one of the model systems for the study on facultative intracellular host adaptation. The effectiveness of nitrogen fixation not only depends on the active transcription of key symbiosis genes (nif/fix) but, also, relies on fine-tuning of the background regulation network in bacteroids. Here, we demonstrated that, in soybean nodules elicited by $S$. fredii, an ancestral zinc finger transcriptional factor MucR1 is dispensable for transcription of nif/fix genes but is required for active expression of transporters for essential elements of nitrogenase (iron, molybdenum, and sulfur), phosphate, and zinc. Soybean plants inoculated with mutants of high-affinity transporters for phosphate or zinc exhibited a typical phenotype of nitrogen starvation, similar to plants inoculated with the mucRl mutant. Taken together with the horizontal transfer potential of the $m u c R$ homolog localized on the symbiosis plasmid (containing key symbiosis genes nod and nif/fix), we hypothesized that MucR might have been recruited in activating conserved local ion transporters to support nitrogen fixation processes in soybean nodules. These findings shed new light on the evolutionary importance of zinc finger-bearing MucR transcriptional factor in symbiotic adaptation.

\section{MATERIALS AND METHODS}

Bacterial strains, plasmids, and growth conditions.

$S$. fredii and Escherichia coli strains and plasmids used in this study are listed in Table 2. S. fredii strains were grown at $28^{\circ} \mathrm{C}$ in TY medium or on yeast extract-mannitol agar medium (Vincent 1970). E. coli strains were cultured in LuriaBertani medium at $37^{\circ} \mathrm{C}$. The concentrations of antibiotics

Table 2. Strains and plasmids used in this study

\begin{tabular}{|c|c|c|}
\hline Names & Descriptions $^{\text {a }}$ & Source \\
\hline \multicolumn{3}{|l|}{ Sinorhizobium fredii } \\
\hline CCBAU45436 & Wild type, $\mathrm{Nal}^{\mathrm{r}}, \mathrm{Gen}^{\mathrm{r}}$ & Tian et al. 2012 \\
\hline тисR1::Tn5 & CCBAU45436 Tn5 insertion in mucRl coding for MucR1 & This work \\
\hline mисR1 & CCBAU45436 $\Delta$ тисR1::Gm, $\mathrm{Nal}^{\mathrm{r}}, \mathrm{Gen}^{\mathrm{r}}$ & This work \\
\hline mucR2 & CCBAU45436 $\Delta m и с R 2:: G m, \mathrm{Nal}^{\mathrm{r}}, \mathrm{Gen}^{\mathrm{r}}$ & This work \\
\hline тисR1/R2 & CCBAU45436 $\Delta m и с R 1, \Delta m и с R 2:: G m, \mathrm{Nal}^{\mathrm{r}}, \mathrm{Gen}^{\mathrm{r}}$ & This work \\
\hline exoA & CCBAU45436 $\triangle$ exoA, $\mathrm{Nal}^{\mathrm{r}}, \mathrm{Gen}^{\mathrm{r}}$ & This work \\
\hline mисR1/vir & CCBAU45436 $\Delta$ тисR1, $\Delta$ virB2-10 ::Gm, $\mathrm{Nal}^{\mathrm{r}}, \mathrm{Gen}^{\mathrm{r}}$ & This work \\
\hline zпиА & CCBAU45436 $\Delta z n u A:: G m, \mathrm{Nal}^{\mathrm{r}}, \mathrm{Gen}^{\mathrm{r}}$ & This work \\
\hline pst & CCBAU45436 $\Delta p s t S C A B:: G m, \mathrm{Nal}^{\mathrm{r}}, \mathrm{Gen}^{\mathrm{r}}$ & This work \\
\hline phoB & CCBAU45436 $\Delta p h o B:: G m, \mathrm{Nal}^{\mathrm{r}}, \mathrm{Gen}^{\mathrm{r}}$ & This work \\
\hline \multicolumn{3}{|l|}{ Escherichia coli } \\
\hline DH5 $\alpha$ & $\begin{array}{l}\text { fhuA2 } \Delta \text { (argF-lacZ)U169 phoA glnV44 } \$ 80 \Delta(\text { lacZ)M15 gyrA96 recA1 relA1 endA1 thi-1 } \\
\text { hsdR17 }\end{array}$ & Bethesda Research \\
\hline \multicolumn{3}{|c|}{${ }^{\prime}$} \\
\hline pRK2013 & ColE1, $\mathrm{Tra}^{+}, \mathrm{Km}^{\mathrm{r}}$ & Ditta et al. 1980 \\
\hline pCM157 & IncP plasmid that provides expression of the Cre recombinase, $\mathrm{Tet}^{\mathrm{r}}$ & Marx and Lidstrom 2002 \\
\hline pCM351 & Allelic exchange vector bearing a gentamicin cassette flanked by loxP sites, Gen ${ }^{\mathrm{r}}, \mathrm{Tet}^{\mathrm{r}}$ & Marx and Lidstrom 2002 \\
\hline pRL1063a & Carrying Tn5-1063a, $\mathrm{Km}^{\mathrm{r}}, \mathrm{Bm}^{\mathrm{r}}$ and $\mathrm{Sm}^{\mathrm{r}}$ & Wolk et al. 1991 \\
\hline pBBR1MCS-2 & Broad-host cloning vector, $\mathrm{Km}^{\mathrm{r}}$ & Kovach et al. 1995 \\
\hline $\mathrm{pBmисRl}$ & pBBR1MCS-2 expressing the $m u c R 1$ gene of $S$. fredii CCBAU 45436 & This work \\
\hline $\mathrm{pB}$ тисR2 & pBBR1MCS-2 expressing the mucR2 gene of $S$. fredii CCBAU45436 & This work \\
\hline $\mathrm{pB}$ тисR1+340C & pBmисR1-derived vector carrying a C-insertion at $\mathrm{N}_{340}$ of mucRl ORF & This work \\
\hline $\mathrm{pB}$ тисR2-340C & $\mathrm{pB} m и с R 1$-derived vector carrying a $\mathrm{C}$ deletion at $\mathrm{N}_{340}$ of $m и c R 2 \mathrm{ORF}$ & This work \\
\hline $\mathrm{pB}$ тисR1-BR3PM & pBmисR1-derived vector expressing MucR1 (R125A, R127A) & This work \\
\hline $\mathrm{pB}$ тисR1-BR4D & pBmисR1-derived vector expressing MucR1 (1 to 136 ) & This work \\
\hline $\mathrm{pB} m u c R 1-N G R 234$ & pBBR1MCS-2 expressing the mucRl gene of $S$. fredii NGR234 & This work \\
\hline $\mathrm{pB}$ тисR2-NGR234 & pBBR1MCS-2 expressing the $m u c R 2$ gene of $S$. fredii NGR234 & This work \\
\hline
\end{tabular}

${ }^{\mathrm{a}} \mathrm{Nal}^{\mathrm{r}}, \mathrm{Gen}^{\mathrm{r}}, \mathrm{Km}^{\mathrm{r}}, \mathrm{Tet}^{\mathrm{r}}, \mathrm{Bm}^{\mathrm{r}}$, and $\mathrm{Sm}^{\mathrm{r}}$ indicate resistance to nalidixic acid, gentamycin, kanamycin, tetracycline, bleomycin, and streptomycin. ORF $=$ open reading frame. 
used, when required, for $S$. fredii and $E$. coli cultures were $30 \mu \mathrm{g} / \mathrm{ml}$ for nalidixic acid, $10 \mu \mathrm{g} / \mathrm{ml}$ for trimethoprim, $10 \mu \mathrm{g} / \mathrm{ml}$ for tetracycline, $50 \mu \mathrm{g} / \mathrm{ml}$ for kanamycin, and $30 \mu \mathrm{g} / \mathrm{ml}$ for gentamicin.

\section{Construction of plasmids and mutant strains.}

Primers used for DNA amplification are listed in Supplementary Table S3. For construction of the in-frame gene deletion mutants, we used the cre-lox system (Marx and Lidstrom 2002). PCR fragments encompassing the upstream $\mathrm{N}$-terminal coding region and the downstream C-terminal coding region of the one or more genes to be deleted were sequentially amplified and cloned into each of the two multiple cloning sites of pCM351 by digestion-ligation-transformation manipulation. The resultant pCM351 derivatives with correct cloned sequences, verified by Sanger sequencing (Beijing Genomic Institute [BGI]), were then conjugated into $S$. fredii CCBAU45436 or its derivatives using pRK2013 as the helper plasmid (Ditta et al. 1980; Marx and Lidstrom 2002). To obtain the mutant lacking the gentamicin-resistance gene flanked by two loxP sites, the plasmid pCM157 expressing Cre recombinase was introduced into rhizobial cells by conjugation. Transconjugants sensitive to gentamicin were selected for subsequent screening of pCM157-cured strains, which are tetracycline sensitive (Marx and Lidstrom 2002). $S$. fredii mutants obtained in this study are listed in Table 2 and mutations for selected DEG are visualized in Supplementary Figure S4. Briefly, in-frame deletion mutations were constructed for mucRl and mucR2, both of which are monocistrons. To inactivate the production of EPS and T4SS-III, exoA within exo gene cluster and virB2-virB10 within the T4SS-III gene cluster were replaced with a gentamicin cassette. To block the formation of the high-affinity transporter for phosphate and zinc, in-frame deletion mutants of pstSCAB and the monocistron znuA, respectively, were constructed. Moreover, an in-frame deletion mutant of the phosphate starvation regulator gene $p h o B$, which is downstream of $p s t S C A B$, was constructed to check whether the symbiotic defect of the pstSCAB mutant was due to a potential polar effect on the expression $p h o B$.

To construct the plasmids expressing mucR homologs, the fragments containing coding sequences of $m u c R$ homologs from $S$. fredii strains CCBAU45436 and NGR234 and upstream promoter regions were cloned into a multiple cloning site of pBBR1MCS-2 (Kovach et al. 1995). Four plasmids were obtained, i.e., $\mathrm{pB} m u c R 1, \mathrm{pB} m u c R 2$, $\mathrm{pB} m u c R 1-N G R 234$, and $\mathrm{pB} m u c R 2-$

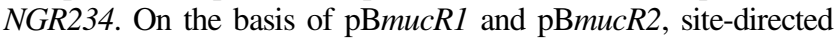
mutagenesis was performed using a Phusion site-directed mutagenesis kit (Thermo Scientific) to introduce the singlenucleotide insertion or deletion or truncation of MucR1 at $\mathrm{C}$-terminal basic regions. This resulted in $\mathrm{pBmucR} 1+340 C$ (insertion), $\mathrm{pB} m u c R 2-340 C$ (deletion), $\mathrm{pB} m u c R 1-B R 3 P M$ (point mutations at the third basic region, R125A and R127A),

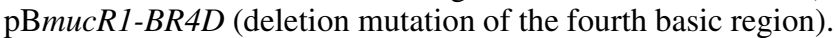
All constructs were verified by PCR and Sanger sequencing in E. coli and by PCR in S. fredii. Plasmids were transferred from E. coli to $S$. fredii by triparental mating using pRK2013 as the helper plasmid.

\section{Plant assays, nitrogenase activity assays, and electron microscopy.}

Symbiotic performance of $S$. fredii strains was tested on Glycine max cv. JD17 as previously described (Wang et al. 2015). Seeds of G. $\max \mathrm{cv}$. JD17 were surface-sterilized in $3 \% \mathrm{NaClO}$ (wt/vol) solution, were germinated, and were inoculated with $1 \mathrm{ml}$ of physiological saline $(0.8 \% \mathrm{NaCl})$ suspension of rhizobia with an optical density at $600 \mathrm{~nm}\left(\mathrm{OD}_{600}\right)$ equivalent to 0.2 . Plants were grown for 30 days at $24^{\circ} \mathrm{C}$ with 12 -h day and night cycles, in vermiculate moistened with low-N nutrient solution in Leonard jars (Vincent 1970). Nitrogenase activity of nodules was measured using acetylene reduction method as descried previously (Buendia-Claveria et al. 1989). For electron microscopy, ultrathin sections of nodules of 30-days postinoculation (dpi) plants were prepared as described earlier ( $\mathrm{Li}$ et al. 2013) and were observed with a JEM-1230 transmission electron microscope.

\section{RNA-seq and real-time PCR.}

Cultures of free-living cells in TY medium were collected by centrifugation when the $\mathrm{OD}_{600}$ reached about 1.2. Isolation of bacteroids from 30-dpi nodules of $G$. $\max$ cv. JD17 was performed using the approach described earlier ( $\mathrm{Li}$ et al. 2013). RNA from free-living bacteria or bacteroids was extracted using the Qiagen RNeasy mini kit. RNA samples were sent to BGI-Shenzhen for further treatments, library construction, and strand-specific RNA sequencing. Briefly, residual DNA was removed using RNase-free DNase I ( 30 min at $37^{\circ} \mathrm{C}$ ). To remove the ribosomal (r)RNA, total RNA was then treated with Ribo-Zero rRNA removal kit (gram-negative bacteria), according to the manufacturer's instructions. The mRNAenriched RNA was chemically fragmented to 150 to $200 \mathrm{bp}$, using divalent cations under elevated temperature. The firststrand cDNA was synthesized, using reverse transcription and random primers based on the cleaved RNA fragments. During the synthesis of the second strand, nonincorporated nucleotides were removed and dTTP was substituted by dUTP, as described earlier (Parkhomchuk et al. 2009). Then, products with ligated adapters were purified and digested with $\mathrm{N}$-glycosylase (Applied Biosystems) to remove the second-strand cDNA. Fifteen cycles of PCR with phusion polymerase were carried out and the resultant products were sequenced on an Illumina Hiseq 2000 platform. To validate the results of RNA-seq, real-time qPCR was performed for 25 genes with different transcription profiles. Three independent biological replicates were tested. The experimental procedure for qRT-PCR was the same to the one described earlier (Li et al. 2013).

\section{Bioinformatics analyses.}

For RNA-seq data, clean reads in fastq files (90-bp paired end reads) were mapped to the $S$. fredii CCBAU45436 reference sequence using HISAT (-no spliced alignment; -rna-strandness) (Kim et al. 2015). Unique mapped reads for each protein coding gene were extracted from sorted bam files by HTseq-count (Anders et al. 2015). Then, the DEG (FDR $\leq 0.001, \mid \log _{2}$ ratio $\mid \geq$ 1) were identified by DEGseq, using the normalized gene expression data (RPKM) as inputs (Wang et al. 2010). COG annotation for $S$. fredii CCBAU45436 proteins was obtained using a reserved position-specific BLAST against the COG database integrated in WebMGA (Wu et al. 2011b).

\section{Availability of supporting data.}

Raw sequence data from our RNA-seq analysis can be accessed via the National Center for Biotechnology Information Sequence Read Archive server under accession number PRJNA302586, and the complete genome sequence of CCBAU45436 has been deposited under accession number PRJNA285929.

\section{ACKNOWLEDGMENT}

The authors thank M. Ni and H. Lam for assistance in closing gaps of the genome sequence of CCBAU45436. This work was supported by the National Natural Science Foundation of China (31570069), National Basic Research Program of China (973 program 2015CB158300) and Chinese Universities Scientific Fund (2013XJ015). 


\section{LITERATURE CITED}

Agron, P. G., Ditta, G. S., and Helinski, D. R. 1993. Oxygen regulation of nifA transcription in vitro. Proc. Natl. Acad. Sci. U.S.A. 90:3506-3510.

Albareda, M., Rodriguez-Navarro, D. N., and Temprano, F. J. 2009. Use of Sinorhizobium (Ensifer) fredii for soybean inoculants in South Spain. Eur. J. Agron. 30:205-211.

Anders, S., Pyl, P. T., and Huber, W. 2015. HTSeq-A Python framework to work with high-throughput sequencing data. Bioinformatics 31:166-169.

Baglivo, I., Russo, L., Esposito, S., Malgieri, G., Renda, M., Salluzzo, A., Di Blasio, B., Isernia, C., Fattorusso, R., and Pedone, P. V. 2009. The structural role of the zinc ion can be dispensable in prokaryotic zincfinger domains. Proc. Natl. Acad. Sci. U.S.A. 106:6933-6938.

Bahlawane, C., McIntosh, M., Krol, E., and Becker, A. 2008. Sinorhizobium meliloti regulator MucR couples exopolysaccharide synthesis and motility. Mol. Plant-Microbe Interact 21:1498-1509.

Batut, J., Daveran-Mingot, M. L., David, M., Jacobs, J., Garnerone, A. M., and Kahn, D. 1989. fixK, a gene homologous with fnr and $c r p$ from Escherichia coli, regulates nitrogen fixation genes both positively and negatively in Rhizobium meliloti. EMBO (Eur. Mol. Biol. Organ.) J. 8:1279-1286.

Becker, A., Bergès, H., Krol, E., Bruand, C., Rüberg, S., Capela, D., Lauber, E., Meilhoc, E., Ampe, F., de Bruijn, F. J., Fourment, J., Francez-Charlot, A., Kahn, D., Küster, H., Liebe, C., Pühler, A., Weidner, S., and Batut, J. 2004. Global changes in gene expression in Sinorhizobium meliloti 1021 under microoxic and symbiotic conditions. Mol. Plant-Microbe Interact 17:292-303.

Bertram-Drogatz, P. A., Quester, I., Becker, A., and Pühler, A. 1998. The Sinorhizobium meliloti MucR protein, which is essential for the production of high-molecular-weight succinoglycan exopolysaccharide, binds to short DNA regions upstream of exoH and exoY. Mol. Gen. Genet. 257:433-441.

Bittinger, M. A., and Handelsman, J. 2000. Identification of genes in the RosR regulon of Rhizobium etli. J. Bacteriol. 182:1706-1713.

Bittinger, M. A., Milner, J. L., Saville, B. J., and Handelsman, J. 1997. rosR, a determinant of nodulation competitiveness in Rhizobium etli. Mol. Plant-Microbe Interact 10:180-186.

Bouhouche, N., Syvanen, M., and Kado, C. I. 2000. The origin of prokaryotic $\mathrm{C}_{2} \mathrm{H}_{2}$ zinc finger regulators. Trends Microbiol. 8:77-81.

Buendia-Claveria, A. M., Chamber, M., and Ruizsainz, J. E. 1989. A comparative-study of the physiological-characteristics, plasmid content and symbiotic properties of different Rhizobium fredii strains. Syst. Appl. Microbiol. 12:203-209.

Cascales, E., and Christie, P. J. 2003. The versatile bacterial type IV secretion systems. Nat. Rev. Microbiol. 1:137-149.

Caswell, C. C., Elhassanny, A. E. M., Planchin, E. E., Roux, C. M., WeeksGorospe, J. N., Ficht, T. A., Dunman, P. M., and Roop, R. M., 2nd. 2013. Diverse genetic regulon of the virulence-associated transcriptional regulator MucR in Brucella abortus 2308. Infect. Immun. 81:1040-1051.

Chao, T. C., Buhrmester, J., Hansmeier, N., Pühler, A., and Weidner, S. 2005. Role of the regulatory gene rirA in the transcriptional response of Sinorhizobium meliloti to iron limitation. Appl. Environ. Microbiol. 71: 5969-5982.

Chin, N., Frey, J., Chang, C. F., and Chang, Y. F. 1996. Identification of a locus involved in the utilization of iron by Actinobacillus pleuropneumoniae. FEMS (Fed. Eur. Microbiol. Soc.) Microbiol. Lett. 143: $1-6$.

Clarke, V. C., Loughlin, P. C., Day, D. A., and Smith, P. M. C. 2014. Transport processes of the legume symbiosome membrane. Front. Plant Sci. 5:699.

David, M., Daveran, M. L., Batut, J., Dedieu, A., Domergue, O., Ghai, J., Hertig, C., Boistard, P., and Kahn, D. 1988. Cascade regulation of nif gene expression in Rhizobium meliloti. Cell 54:671-683.

Deaker, R., Roughley, R. J., and Kennedy, I. R. 2004. Legume seed inoculation technology — a review. Soil Biol. Biochem. 36:1275-1288.

Delgado, M. J., Tresierra-Ayala, A., Talbi, C., and Bedmar, E. J. 2006. Functional characterization of the Bradyrhizobium japonicum modA and $\bmod B$ genes involved in molybdenum transport. Microbiology 152 : 199-207.

Ditta, G., Stanfield, S., Corbin, D., and Helinski, D. R. 1980. Broad host range DNA cloning system for gram-negative bacteria: Construction of a gene bank of Rhizobium meliloti. Proc. Natl. Acad. Sci. U.S.A. 77:7347-7351.

Dixon, R., and Kahn, D. 2004. Genetic regulation of biological nitrogen fixation. Nat. Rev. Microbiol. 2:621-631.

Geiger, O., Röhrs, V., Weissenmayer, B., Finan, T. M., and Thomas-Oates, J. E. 1999. The regulator gene phoB mediates phosphate stresscontrolled synthesis of the membrane lipid diacylglyceryl-N,N,Ntrimethylhomoserine in Rhizobium (Sinorhizobium) meliloti. Mol. Microbiol. 32:63-73.
Guan, S. H., Gris, C., Cruveiller, S., Pouzet, C., Tasse, L., Leru, A. Maillard, A., Médigue, C., Batut, J., Masson-Boivin, C., and Capela, D. 2013. Experimental evolution of nodule intracellular infection in legume symbionts. ISME J. 7:1367-1377.

Han, L. L., Wang, E. T., Han, T. X., Liu, J., Sui, X. H., Chen, W. F., and Chen, W. X. 2009. Unique community structure and biogeography of soybean rhizobia in the saline-alkaline soils of Xinjiang, China. Plant Soil 324:291-305.

Hsieh, Y.-J., and Wanner, B. L. 2010. Global regulation by the sevencomponent Pi signaling system. Curr. Opin. Microbiol. 13:198-203.

Janczarek, M., Kutkowska, J., Piersiak, T., and Skorupska, A. 2010. Rhizobium leguminosarum bv. trifolii rosR is required for interaction with clover, biofilm formation and adaptation to the environment. BMC Microbiol. 10:284.

Janczarek, M., and Skorupska, A. 2007. The Rhizobium leguminosarum bv. trifolii RosR: Transcriptional regulator involved in exopolysaccharide production. Mol. Plant-Microbe Interact 20:867-881.

Jones, K. M., Lloret, J., Daniele, J. R., and Walker, G. C. 2007. The type IV secretion system of Sinorhizobium meliloti strain 1021 is required for conjugation but not for intracellular symbiosis. J. Bacteriol. 189: 2133-2138.

Keller, M., Roxlau, A., Weng, W. M., Schmidt, M., Quandt, J., Niehaus, K., Jording, D., Arnold, W., and Pühler, A. 1995. Molecular analysis of the Rhizobium meliloti mucR gene regulating the biosynthesis of the exopolysaccharides succinoglycan and galactoglucan. Mol. Plant-Microbe Interact 8:267-277.

Kim, D., Langmead, B., and Salzberg, S. L. 2015. HISAT: A fast spliced aligner with low memory requirements. Nat. Methods 12:357-360.

Kobayashi, H., Naciri-Graven, Y., Broughton, W. J., and Perret, X. 2004. Flavonoids induce temporal shifts in gene-expression of nod-box controlled loci in Rhizobium sp. NGR234. Mol. Microbiol. 51:335-347.

Kovach, M. E., Elzer, P. H., Hill, D. S., Robertson, G. T., Farris, M. A., Roop, R. M., 2nd, and Peterson, K. M. 1995. Four new derivatives of the broad-host-range cloning vector pBBR1MCS, carrying different antibioticresistance cassettes. Gene 166:175-176.

Krishnan, H. B., Lorio, J., Kim, W. S., Jiang, G., Kim, K. Y., DeBoer, M., and Pueppke, S. G. 2003. Extracellular proteins involved in soybean cultivar-specific nodulation are associated with pilus-like surface appendages and exported by a type III protein secretion system in Sinorhizobium fredii USDA257. Mol. Plant-Microbe Interact 16:617-625.

Li, Y., Tian, C. F., Chen, W. F., Wang, L., Sui, X. H., and Chen, W. X. 2013. High-resolution transcriptomic analyses of Sinorhizobium sp. NGR234 bacteroids in determinate nodules of Vigna unguiculata and indeterminate nodules of Leucaena leucocephala. PLoS One 8:e70531.

Malgieri, G., Palmieri, M., Russo, L., Fattorusso, R., Pedone, P. V., and Isernia, C. 2015. The prokaryotic zinc-finger: Structure, function and comparison with the eukaryotic counterpart. FEBS J. 282:4480-4496.

Man, C. X., Wang, H., Chen, W. X. F. X. F., Sui, X. H., and Wang, E. T. 2008. Diverse rhizobia associated with soybean grown in the subtropical and tropical regions of China. Plant Soil 310:77-87.

Manian, S. S., Gumbleton, R., and Gara, F. O. 1982. The role of formate metabolism in nitrogen fixation in Rhizobium spp. Arch. Microbiol. 133: 312-317.

Marchetti, M., Capela, D., Glew, M., Cruveiller, S., Chane-Woon-Ming, B., Gris, C., Timmers, T., Poinsot, V., Gilbert, L. B., Heeb, P., Médigue, C., Batut, J., and Masson-Boivin, C. 2010. Experimental evolution of a plant pathogen into a legume symbiont. PLoS Biol. 8:e1000280.

Marx, C. J., and Lidstrom, M. E. 2002. Broad-host-range cre-lox system for antibiotic marker recycling in gram-negative bacteria. Biotechniques 33: 1062-1067.

Masson-Boivin, C., Giraud, E., Perret, X., and Batut, J. 2009. Establishing nitrogen-fixing symbiosis with legumes: How many rhizobium recipes? Trends Microbiol. 17:458-466.

Moreau, S., Thomson, R. M., Kaiser, B. N., Trevaskis, B., Guerinot, M. L., Udvardi, M. K., Puppo, A., and Day, D. A. 2002. GmZIP1 encodes a symbiosis-specific zinc transporter in soybean. J. Biol. Chem. 277: 4738-4746.

Mueller, K., and González, J. E. 2011. Complex regulation of symbiotic functions is coordinated by MucR and quorum sensing in Sinorhizobium meliloti. J. Bacteriol. 193:485-496.

Nelson, M. S., and Sadowsky, M. J. 2015. Secretion systems and signal exchange between nitrogen-fixing rhizobia and legumes. Front. Plant Sci. 6:491.

Netti, F., Malgieri, G., Esposito, S., Palmieri, M., Baglivo, I., Isernia, C., Omichinski, J. G., Pedone, P. V., Lartillot, N., and Fattorusso, R. 2013. An experimentally tested scenario for the structural evolution of eukaryotic $\mathrm{Cys}_{2} \mathrm{His}_{2}$ zinc fingers from eubacterial ros homologs. Mol Biol. Evol. 30:1504-1513. 
Parkhomchuk, D., Borodina, T., Amstislavskiy, V., Banaru, M., Hallen, L., Krobitsch, S., Lehrach, H., and Soldatov, A. 2009. Transcriptome analysis by strand-specific sequencing of complementary DNA. Nucleic Acids Res. 37:e123.

Patzer, S. I., and Hantke, K. 1998. The ZnuABC high-affinity zinc uptake system and its regulator Zur in Escherichia coli. Mol. Microbiol. 28: 1199-1210.

Peix, A., Ramírez-Bahena, M. H., Velázquez, E., and Bedmar, E. J. 2015. Bacterial associations with legumes. Crit. Rev. Plant Sci. 34:17-42.

Pueppke, S. G., and Broughton, W. J. 1999. Rhizobium sp. strain NGR234 and $R$. fredii USDA257 share exceptionally broad, nested host ranges. Mol. Plant-Microbe Interact 12:293-318.

Remigi, P., Zhu, J., Young, J. P. W., and Masson-Boivin, C. 2015. Symbiosis within symbiosis: Evolving nitrogen-fixing legume symbionts. Trends Microbiol. 24:63-75.

Roche, P., Maillet, F., Plazanet, C., Debellé, F., Ferro, M., Truchet, G., Promé, J. C., and Dénarié, J. 1996. The common nodABC genes of Rhizobium meliloti are host-range determinants. Proc. Natl. Acad. Sci. U.S.A. 93:15305-15310.

Rodríguez-Navarro, D. N., Bellogin, R., Camacho, M., Daza, A., Medina, C., Ollero, F. J., Santamaria, C., Ruiz-Sainz, J. E., Vinardell, J. M., and Temprano, F. J. 2003. Field assessment and genetic stability of Sinorhizobium fredii strain SMH12 for commercial soybean inoculants. Eur. J. Agron. 19: 299-309.

Rodríguez-Navarro, D. N., Rodríguez-Carvajal, M. A., Acosta-Jurado, S., Soto, M. J., Margaret, I., Crespo-Rivas, J. C., Sanjuan, J., Temprano, F., Gil-Serrano, A., Ruiz-Sainz, J. E., and Vinardell, J. M. 2014. Structure and biological roles of Sinorhizobium fredii $\mathrm{HH} 103$ exopolysaccharide. PLoS One 9:e115391.

Schmeisser, C., Liesegang, H., Krysciak, D., Bakkou, N., Le Quéré, A., Wollherr, A., Heinemeyer, I., Morgenstern, B., Pommerening-Röser, A., Flores, M., Palacios, R., Brenner, S., Gottschalk, G., Schmitz, R. A., Broughton, W. J., Perret, X., Strittmatter, A. W., and Streit, W. R. 2009. Rhizobium sp. strain NGR234 possesses a remarkable number of secretion systems. Appl. Environ. Microbiol. 75:4035-4045.

Skorupska, A., Janczarek, M., Marczak, M., Mazur, A., and Król, J. 2006. Rhizobial exopolysaccharides: Genetic control and symbiotic functions. Microb. Cell Fact. 5:7.

Sugawara, M., Epstein, B., Badgley, B. D., Unno, T., Xu, L., Reese, J., Gyaneshwar, P., Denny, R., Mudge, J., Bharti, A. K., Farmer, A. D., May, G. D., Woodward, J. E., Médigue, C., Vallenet, D., Lajus, A., Rouy, Z., Martinez-Vaz, B., Tiffin, P., Young, N. D., and Sadowsky, M. J. 2013. Comparative genomics of the core and accessory genomes of 48 Sinorhizobium strains comprising five genospecies. Genome Biol. 14:R17.

Sugawara, M., Shah, G. R., Sadowsky, M. J., Paliy, O., Speck, J., Vail, A. W., and Gyaneshwar, P. 2011. Expression and functional roles of Bradyrhizobium japonicum genes involved in the utilization of inorganic and organic sulfur compounds in free-living and symbiotic conditions. Mol. Plant-Microbe Interact 24:451-457.

Sullivan, J. T., Patrick, H. N., Lowther, W. L., Scott, D. B., and Ronson, C. W. 1995. Nodulating strains of Rhizobium loti arise through chromosomal symbiotic gene transfer in the environment. Proc. Natl. Acad. Sci. U.S.A. 92:8985-8989.

Sullivan, J. T., and Ronson, C. W. 1998. Evolution of rhizobia by acquisition of a 500-kb symbiosis island that integrates into a phe-tRNA gene. Proc. Natl. Acad. Sci. U.S.A. 95:5145-5149.

Tian, C. F., Zhou, Y. J., Zhang, Y. M., Li, Q. Q., Zhang, Y. Z., Li, D. F., Wang, S., Wang, J., Gilbert, L. B., Li, Y. R., and Chen, W. X. 2012.
Comparative genomics of rhizobia nodulating soybean suggests extensive recruitment of lineage-specific genes in adaptations. Proc. Natl. Acad. Sci. U.S.A. 109:8629-8634.

Toft, C., and Andersson, S. G. E. 2010. Evolutionary microbial genomics: Insights into bacterial host adaptation. Nat. Rev. Genet. 11:465-475.

Turner, S. L., and Young, J. P. W. 2000. The glutamine synthetases of rhizobia: Phylogenetics and evolutionary implications. Mol. Biol. Evol. 17:309-319.

Udvardi, M., and Poole, P. S. 2013. Transport and metabolism in legumerhizobia symbioses. Annu. Rev. Plant Biol. 64:781-805.

Vahling-Armstrong, C. M., Zhou, H., Benyon, L., Morgan, J. K., and Duan, Y. 2012. Two plant bacteria, S. meliloti and $C a$. Liberibacter asiaticus, share functional $z n u A B C$ homologues that encode for a high affinity zinc uptake system. PLoS One 7:e37340.

van der Ploeg, J. R., Iwanicka-Nowicka, R., Kertesz, M. A., Leisinger, T., and Hryniewicz, M. M. 1997. Involvement of CysB and Cbl regulatory proteins in expression of the $\operatorname{tau} A B C D$ operon and other sulfate starvationinducible genes in Escherichia coli. J. Bacteriol. 179:7671-7678.

Vincent, J. M. 1970. A Manual for the Practical Study of Root Nodule Bacteria. Blackwell, Oxford.

Wang, L., Feng, Z., Wang, X., Wang, X., and Zhang, X. 2010. DEGseq: An $\mathrm{R}$ package for identifying differentially expressed genes from RNA-seq data. Bioinformatics 26:136-138.

Wang, D., Wang, Y. C., Wu, L. J., Liu, J. X., Zhang, P., Jiao, J., Yan, H., Liu, T., Tian, C. F., and Chen, W. X. 2015. Construction and pilot screening of a signature-tagged mutant library of Sinorhizobium fredii. Arch. Microbiol. 198:91-99.

Weidner, S., Becker, A., Bonilla, I., Jaenicke, S., Lloret, J., Margaret, I., Pühler, A., Ruiz-Sainz, J. E., Schneiker-Bekel, S., Szczepanowski, R. Vinardell, J. M., Zehner, S., and Göttfert, M. 2012. Genome sequence of the soybean symbiont Sinorhizobium fredii HH103. J. Bacteriol. 194: 1617-1618

Wolk, C. P., Cai, Y., and Panoff, J.-M. 1991. Use of a transposon with luciferase as a reporter to identify environmentally responsive genes in a cyanobacterium. Proc. Natl. Acad. Sci. U.S.A. 88:5355-5359.

Wu, L. J., Wang, H. Q., Wang, E. T., Chen, W. X., and Tian, C. F. 2011a. Genetic diversity of nodulating and non-nodulating rhizobia associated with wild soybean (Glycine soja Sieb. \& Zucc.) in different ecoregions of China. FEMS (Fed. Eur. Microbiol. Soc.) Microbiol. Ecol. 76 439-450.

Wu, S., Zhu, Z., Fu, L., Niu, B., and Li, W. 2011b. WebMGA: A customizable web server for fast metagenomic sequence analysis. BMC Genomics 12:444.

Yang, S., Tang, F., Gao, M., Krishnan, H. B., and Zhu, H. 2010. R gene-controlled host specificity in the legume-rhizobia symbiosis. Proc. Natl. Acad. Sci. U.S.A. 107:18735-18740.

Yuan, Z. C., Zaheer, R., and Finan, T. M. 2006. Regulation and properties of PstSCAB, a high-affinity, high-velocity phosphate transport system of Sinorhizobium meliloti. J. Bacteriol. 188:1089-1102.

Zavaleta-Pastor, M., Sohlenkamp, C., Gao, J. L., Guan, Z., Zaheer, R., Finan, T. M., Raetz, C. R., López-Lara, I. M., and Geiger, O. 2010. Sinorhizobium meliloti phospholipase C required for lipid remodeling during phosphorus limitation. Proc. Natl. Acad. Sci. U.S.A. 107: 302-307.

Zhang, Y. M., Li, Y., Jr., Chen, W. F., Wang, E. T., Tian, C. F., Li, Q. Q., Zhang, Y. Z., Sui, X. H., and Chen, W. X. 2011. Biodiversity and biogeography of rhizobia associated with soybean plants grown in the North China Plain. Appl. Environ. Microbiol. 77:6331-6342. 